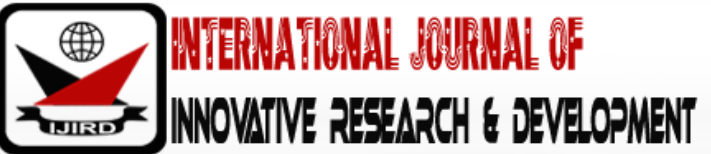

ISSN 2278-0211 (Online)

\section{Culture, Training, Technological Application and Crime Investigation Effectiveness across Commercial Crime Investigative Units in Nigeria: An Empirical Analysis}

\author{
Dr. Nwonyi Polycarp Emeka \\ Deputy Commissioner, Department of Research and Planning of Nigeria Police Force, Force \\ Headquarters Annex,Kam Salem House, Lagos, Nigeria
}

\begin{abstract}
:
Crime investigation is an important law enforcement activity.It is one of the least studied law enforcement functions. Generally, criminal investigation is viewed as a 'truth finding' process at the end of which the crime is solved, and offenders are caught. This study therefore investigated culture, training, technological application and crime investigation effectiveness across commercial crime investigative units in Nigeria.

This study used a descriptive survey design of ex-post-facto type. One thousand and two hundred participants, selected through a combination of purposive and stratified random sampling techniques were drawn from commercial crime investigating units of the Police, EFCC, Customs and NDLEA in Lagos State. Data were collected using two adopted and three adapted instruments. The reliability coefficients yielded by the instruments were: Agency Culture Inventory, 0.88; Training Effectiveness Scale, 0.73; Technology Application Inventory, 0.91; and Commercial Crime Investigators Effectiveness Scale, 0.81. Three null hypotheses were tested at 0.05 level of significance, while data were analyzed using of means, standard deviation and Multiple Regression Analysis.

The findings of this study indicated the results indicated significant mean differences in the influence of agency culture $\left(F_{(4,1179)}=4.765, p=.000\right)$, training $\left(F_{(4,1179)}=8.306, p=.007\right)$, and technological application $\left(F_{(4,1179)}=5.160, p=\right.$ $.000)$ on commercial crime investigators' effectiveness based on agency type.

It is therefore concluded that agency culture, training and application of technology has substantial impact on law enforcement practices. In addition, any positive relationship that exists between agency culture, training and application of technology by the agency improves the quality of investigation and performance of law enforcement agencies.
\end{abstract}

Keywords:Agency culture, training, technology application, commercial crime investigators, effectiveness

\section{Introduction}

Commercial Crime is world phenomena and with course of time it is going to be a complicated one. All over the world especially in technologically developed countries, criminologists, detectives are adopting new methods to beat the crime through latest criminal investigation techniques. But in a country like Nigeria, the sources of criminal investigation especially in commercial crimes are mostly the same as it were in the past (Nwonyi, 2014). The factors responsible for the upsurge in crime have been located in the advent of globalization with its attendant rapid social change driven by information and communication technology (ICT). Most of these changes bring improvements in our lives. But they equally breed culture of discontent: a level of aspirations that far exceeds the bound of an individual's local opportunities.

The commercial crime investigators are very critical societal agents for the attainment, preservation and promotion of security in the society. However, security and investigation are necessary conditions for development in any given society. Therefore, the commercial crime investigators could play an important role in the sustenance of an enabling environment for development. In order to maintain order and enforce the law, the commercial crime investigators are endowed by the Constitution and laws with enormous powers of surveillance, to arrest, investigate, search, seize, interrogate, detain, bail and prosecute (Alemika, 2003).Commercial Crime Investigators (CCI) therefore, are trained personnel charged with the responsibility of investigating commercial crimes \{e.g., EFCC, Criminal Investigation Department (CID) in the police like SFU (Special Fraud Unit)\}. Commercial crime investigators in Nigeria are the investigation departments in Police force, Economic and Financial Crime Commission (EFCC), Nigeria Drug and Law Enforcement Agency (NDLEA), and Nigeria Custom.

In an effort to reduce the menace of corruption in Nigeria, the government has taken several measures among which are the establishment of the Independent Corrupt Practices Commission (ICPC), the Economic and Financial Crimes Commission (EFCC)as complimentary law enforcement agencies for fighting corruption. This was in line with the implementation of the recommendations of the Justice KayodeEsho Commission of Inquiry, strengthening of institutions 
such as NAFDAC and substantially raising the manpower strength, equipment and mobility of the Police. However, a lot still remains to be done to attain the level of security and the administration of justice, which Nigerians deserve.

The Economic and Financial Crimes Commission (EFCC) is a Nigerian law enforcement agency that investigates financial crimes such as advance fee fraud(419 fraud) and money laundering. The EFCC was established in 2003, partially in response to pressure from the Financial Action Task Force on Money Laundering (FATF), which named Nigeria as one of 23 countries non-cooperative in the international community's efforts to fight money laundering (The Establishment Act, 2003).

\subsection{Agency Culture and Commercial Crime Investigators Effectiveness}

Organizations as mini societies have cultures just as societies also have cultures. Culture is critical to understanding any society or group. Through the process of socialization individuals align into groups. Groups have the capacity to shape, influence, and determine group members' views, outlooks, outputs, attitudes and indeed behaviours. Organizations are created to solve societal problems. Organizations employ individuals to assist them in the task of solving their assigned societal problems. The behavioural interface among organizational members creates a pattern of behaviours, values and attitudes that can be discerned, isolated and identified as peculiar organizational culture. This tally with Hills and Jones (2001) assertion that organizational culture is the collection of values and norms that are shared by people and groups in an organization and control the way they interact with each other and with stakeholders outside the organization'.

Agency culture is the fundamental assumptions that guide and determine how organizational problems are solved. It indeed influences the way problems are solved, management is structured and work is done. Glasister and Buckley (1998) are of the view that organizational culture is one of the factors responsible for corporate effectiveness. Denison (1985), and Peters and Waterman (1982) identify organizational culture as the basis for the differences among American firms and Japanese organizations.

Organizational culture is widely accepted in Europe, Asia and America as a tool that causes change on other variables including corporate effectiveness (Ambroz\&Praprotnik, 2008; Fey \& Denison, 2000; Olson \& Gough, 2005). Organizational culture measures are validated as involvement, consistency, adaptability and mission traits (Ambroz\&Praprotnik, 2008; Denison, Javonics, Young \& Cho, 2006). Involvement trait measures the extent to which the participation of employees in organizational decision-making results to a consensus of responsibility and commitment to corporate goals. Consistency measures how employees shared values, beliefs and symbols result to employees coordinated actions. Adaptability trait measures how organizations system of behaviours and structures increase their capacities to survive in their environment. Shared mission trait measures how employees shared understanding of the functions, purposes and objectives of organizations result to effective corporate commitment and performance.

In Nigeria, agency culture is recognized as a theoretical and practical issue in managing organizations (Ewurum, 1999; Glenn, 2002; Yamere\&Odiri, 2002). The concept is embraced by both private and public sector organizations in Nigeria. To buttress this, Yamere (2006) asserts that 'there is a culture of safety at Shell Petroleum Development Company, a culture of poor service at Power Holding Company of Nigeria and a culture of corruption in the civil service'.

Corporate effectiveness entails achieving corporate objectives. Etzioni (1999) stated that 'the actual effectiveness of a specific organization is determined by the extent to which it realizes its goals'. There are several dimensions to defining and measuring corporate effectiveness though it is generally agreed that all the variables need to be operationalized in any given study (Mullins, 2007, Saasongu, 2012). Corporate effectiveness measures are operationalized for this study as profitability, productivity and employee motivation. Profitability is the degree to which a business is profitable. Productivity indicates the efficiency of utilization of organisational resources and balances the efforts among economic, social, technical and environmental objectives. Employee motivation is the inner force that induces or encourages employees to put in their best efforts towards the attainment of goals of organizations (Saasongu, 2012).

Kiely and Peek (2002) studied the culture of the British police. The purpose of the study was to explore police culture and the perceived meanings of 'quality' and 'quality of service' in the police context. At the Police Staff College, the definition of culture suggested by crime investigator academic staff is that offered by Schein (Kiely\& Peek, 2002). A pattern of basic assumptions invented, discovered or developed by a given group as it learns to cope with its problem of external adaptation and internal integration - that has worked well enough to be considered valid and, therefore, to be taught to new members in the correct way to perceive, think and feel in relation to those problems.

In this definition, they used the shared values perspective, rather than the shared practices perspective. They found several organizational values. For example, crime investigator inspectors viewed as important values such as honesty, morality and integrity, providing a good service, value for money, and a desire to help. Others included: commitment, self-discipline and restraint, courtesy, empathy and sympathy, fairness, and impartiality. Loyalty, consistency, trust, and sense of humor also featured. The degree to which police inspectors and sergeants espoused values that were felt to match those of the organization was explored by Kiely and Peek (2002). Some considered their values matched those, stated in some form or other, by Chief Officers. Others argued their values were reflected in published annual objectives. Interviewed inspectors and sergeants felt that most members of the organization shared the values of the police service. The view was expressed that what could differ was the degree of emphasis on particular values or differences in priorities. The realities of crime investigators' work were highlighted as 'tarnishing' values - particularly those of young recruits. The greatest perceived influence was the 'canteen culture.' They learn their values eight hours a day, spending long periods of time sitting in cars watching how other policemen do their job, eating with them, socializing with them. Dangers of 'canteen culture' with youngsters being influenced by 'old cynics' and picking up outdated values were repeatedly alluded to. 
To those interviewed, quality of service signified 'serving the community,' 'value for money,' 'just doing the best you can with the resources available,' and 'the public getting the service they fund us to supply.' Half of those interviewed perceived quality of service to include internal quality, for example, service to the people within the agency, in other words the way they treat each other.

\subsection{Training and Commercial Crime Investigators Effectiveness}

The findings of Collins (2008) on the effect of on-the-job training on commercial crime investigators revealed that training brings greater confidence on workers, enriches employee's knowledge and increased performance skill, creates greater efficiency and effectiveness, increases productivity and leads to higher profitability. The study further revealed that there exists a direct relationship between manpower training and productivity of workers. Training improves the productivity of employees and that of the organization and increases profitability arising from staff efficiency.

- Quick and efficient service to customers;

- Eliminating waste through competitive job performance;

- Low labour turnover;

- Rapid expansion of the organization;

- Increase in the network of the organization human capital; and

- Gain government recognition as responsible corporate citizens.

According to Nickels (2009) the effects of training on employee's performance can often encourage growth within the worker and the organization itself. Training can lead to self-fulfilling prophecy of enhanced output by employee, employee development equals decrease operational costs, leads to greater loyalty to the organization and as well enhanced job satisfaction. He further said that the effects of training on employee performance include meeting and exceeding expectations, cross training of staff, preparing employees for promotion, maintaining a safe environment and reduction of errors.

Also, the findings of the study carried out by Grips and Savermann (2010) revealed that training of agents had significant effects on the productivity of workers in the organization. In the same vein, Laplargne and Bensted (1999) are of the opinion that labour productivity growth appears to be enhanced by the joint introduction of training and innovation. This is due to the fact that training requires the support of innovation to benefit labour productivity growth.

\subsection{Technological Application and Commercial Crime Investigators' Effectiveness}

Lin et al. (2004) examined the perceived ease of use and perceived usefulness for the COPLINK. This framework, basically, is a combination of the TAM and the TPB. They measured perceived usefulness and perceived ease of use in terms of subjective norms, availability, job relevance, output quality, result demonstrability, external data exchange, efficiency gains, and self-efficacy. Results from preliminary evaluations of COPLINK showed that individual officers placed great importance on task performance efficiency resulting from their use of a technology (Lin et al, 2004). This study found that perceived usefulness may be the single most important factor in individual officers' technology acceptance decision making. Perceived usefulness appears to be the only construct that has a significant direct effect on behavioral intention.

In their study validating the use of TAM on police officers, Colvin and Goh (2005) determined that TAM findings were supported empirically in law enforcement settings. A patrol officer who accepted new technology would be facilitated by increasing the ease of use and perceived usefulness. Their findings suggested that the new factors of information quality and timeliness were the most important components of technology acceptance by patrol officers (Colvin \& Goh, 2005).

Timeliness elements were defined as timely access to information and timely response to calls for service. Given the potentially dangerous situations in which law enforcement officers performed their jobs, placing importance on the quality and timeliness of information might prevent fatal outcomes. The findings also implied that administrators should be clear about the purpose of new technology.

Zaworski (2005) examined the impact of the Automated Regional Justice Information System (ARJIS) on police officers to find out whether an information sharing system has any effect on policing performance. He focused on individual effectiveness, job performance, productivity, investigative support, arrests, and clearances in terms of technology effectiveness. In his experimental study, one of the two groups was assigned to use the ARJIS system. He found significant results for these variables, except for the arrest factor, between his subject groups.

Pekgozlu (2003) conducted a study for end-users of POLNET in 2003. He stated that there is a high correlation between end-users' participation and the success of the project based on information technology. Usability features of endusers may influence the system's performance positively or negatively in accordance with their participation to the system. He added that end users may resist the system because of the inappropriate system design, their confusion or distrust to the system, and their negative attitudes about the system. This resistance may go further and even leads to the sabotage. In addition, he also mentioned that end-users' too high expectations about the system may result in disappointment and distrust of the system.

In his study, Pekgozlu (2003) found that even when the end-users' knowledge about computers is only at an average level, they are liable to trust the computers' technology and the POLNET system. End-users think that computers and the POLNET system contribute a lot to their work, but they also are concerned that some projects in the POLNET system do not completely meet the needs of their work. They also think that using the POLNET system is relatively easy and it is not perceived as an obstacle to their decision-making process. In addition, $61.5 \%$ of the end-users think that the 
POLNET system increases the Turkish police's prestige and status and thus they have a positive attitude to the POLNET system (Pekgozlu, 2003).

In his master's thesis, Tosun (2006) conducted a study to test the attitude and perception of Turkish police officers, working in Istanbul, toward the Mobile Information System (MOBESE) system terminals mounted in police cars by utilizing TAM. As external factors, he chose police officers' tenure of job, their user experience with computer, and user satisfaction of MOBESE system. He found that perceived usefulness, perceived ease of use, and attitude toward MOBESE usage are positively related to system usage.

There are many studies focusing on the acceptance and diffusion of information technology systems in North America (Vankatesh\& Davis, 2000; Yi, et al., 2006). Compared to the number of American studies, there are relatively few studies conducted outside of North America (McCoy, 2002). McCoy (2002) and McCoy, et al. (2005) pointed out that though the researchers claimed that culture had a moderate effect on information technology acceptance, they did not collect data related to culture and they could not empirically prove that the variance in the results stemmed from culture.

Mao et al (2005) conducted a comparative study examining user behaviors related to cell-phones in Turkey and the United States. They focused on how the adoption of cell phones changes across two cultures. As hypothesized, their results differed in terms of technology acceptance and adoption of innovations. For instance, they found that perceived ease of use to intention to use was significant for the Turkish sample, but not significant for the Americans. They attributed these differences to cultural and economic structural differences.

\subsection{Hypotheses}

The following hypotheses were formulated for testing at 0.05 level of significance.

- There is no significant mean difference in the influence of agency culture on commercial crime investigators' effectiveness based on agency type.

- There is no significant mean difference in the influence of in-service training on commercial crime investigators' effectiveness based on agency type.

- There is no significant mean difference in the influence of technological application on commercial crime investigators' effectiveness based on agency type.

\section{Methodology}

\subsection{Research Design}

This study adopted a descriptive survey design of ex-post-facto type. This survey design was preferred since the researcher cannot control the conditions experienced by the subjects.

\subsection{Population}

This study comprised of commercial crime investigative units of the Police (SFU) with a population of 901, EFCC with 750, Customs with 697 and NDLEA with 515 within the Federal operational command in Lagos State, Nigeria.

\subsection{Sample and Sampling Technique}

One thousand and two hundred participants were selected through purposive and stratified random sampling techniques. First, the Police, EFCC, Customs and NDLEA in Federal operational command in Lagos State, Nigeria was selected purposively because the four agencies are involved in the investigation of commercial crimes in Nigeria. A sample size of 300 respondents was selected respectively from each of the commercial crime investigative outfits - Police, EFCC, Customs and NDLEA, making a total of 1200 in all. Instruments:

\subsection{Agency Culture Inventory (ACI)}

Agency culture was measured by adopting Agency Culture Inventory by Hee-jae (2000). This instrument consists of 60 items and was designed to capture four dimensions of agency culture (organizational structure), namely involvement, consistency, adaptability and mission. All sub-scales employ a four-point scale, ranging from 1 (strongly disagree) to 4 (strongly agree). The internal consistency measured by Cronbach alphas for overall agency culture inventory and for involvement, consistency, adaptability and mission sub-scales are 0.88, 0.90, 0.88, 0.81 , and 0.92 respectively (Hee-jae, 2000). In Nigeria, the instrument has also been used by Oledikwa and Nbang (2006).

\subsection{Training Effectiveness Scales (TES)}

Commercial crime investigators' training was measured by the South Carolina Law Enforcement Training Survey developed by Rojek, Kaminski, Smith, and Scheer (2007). This instrument questionnaire has been used in more than 65 agencies in the United States of America. For the purpose of this study, the internal consistency of this instrument was established using Cronbach alpha which yielded a coefficient of 0.73

\subsection{Technology Application Inventory (TAI)}

This scale assesses how competent Commercial Crime Investigators are in ICT tools and program operations; while section $\mathrm{C}$ was adapted from the work Abida and Irfan (2010), which was an earlier adaptation from seven factors of computer application originally developed by seven authors namely Venkatesh and Davis (2000) for intention to use, Thompson, Higgins and Howell (1991) for job fit, Venkatesh and Davis (2000) for perceived ease of use, 
Bhattacherjee(2000) for attitude, Taylor and Todd (1995) for facilitating conditions, Teo (2008) for affect towards usage, and Venkatesh and Davis (2000) for voluntariness.

\subsection{Commercial Crime Investigators Effectiveness Survey (CCIES)}

Crime investigators effectiveness scale developed by Osterburg (1962) was adopted in this study. It has 24 items. The scale was developed to ascertain certain law enforcement current practices in line with their operation, selection, training, evaluation, investigation, job description, work requirement/methodology, and desirable experiences. A fourpoint response was employed, ranging from 'very weak' to 4 'very good'. In this study the internal consistency index for the scale using Cronbach alpha was 0.87 .

\subsection{Procedure}

The researcher and four research assistants were involved in the administration of the instruments to each of the sample respondents chosen. The research assistants were postgraduate students of Babcock University trained for the purpose of this study. They were given an orientation on the research and how to carry out the administration of the questionnaires.

\subsection{Method of Data Analysis}

The data collected in this study were analyzed using both descriptive and inferential statistics. The descriptive tools of mean and standard deviation scores were used to describe the commercial crime investigators effectiveness. The hypotheses generated to guide the study were tested by the Multiple Regression Analysis tested at the 0.5 level of significance.

\section{Results and Discussion}

\begin{tabular}{|c|c|c|c|c|c|c|c|}
\hline & & & & \multicolumn{3}{|c|}{ Mean Difference } & Police \\
\hline Agencies & N & Mean & SD & Customs & EFCC & NDLEA & \\
\hline Customs & 294 & 149.38 & 43.20 & & & & \\
\hline EFCC & 297 & 153.99 & 36.82 & & -4.61 & & \\
\hline NDLEA & 295 & 141.54 & 51.10 & & & 12.45 & -23.23 \\
\hline Police & 293 & 164.77 & 32.82 & & & & \\
\hline Total & 1179 & & & & & & \\
\hline
\end{tabular}

Table 1: Summary Table of TukeyPosthoc Tests Showing the Mean Differences in Agency Culture *The Mean Is Significant at the 0.05 Level

\begin{tabular}{|c|c|c|c|c|c|}
\hline & Sum of Squares & Df & Mean Square & F & Sig. \\
\hline Between Groups & 76.284 & 4 & 19.071 & 4.765 & .000 \\
\hline Within Groups & 4725.850 & 1175 & 4.022 & & \\
\hline Total & 4802.134 & 1179 & \multicolumn{3}{|l}{} \\
\hline
\end{tabular}

Table 2: Summary Table of One-Way ANOVA Showing Difference in Commercial Crimes Investigation Agencies Effectiveness Based on Agency Culture

The results presented in Table 1 revealed the mean and standard deviation scores for the Custom, EFCC, NDLEA, and Police as 149.38, 153.99, 141.54 and 164.77 respectively. The result in Table 2 showed a significant influence of agency culture on commercial crime investigators' effectiveness based on agency type $\left(F_{(4,1179)}=4.765, \mathrm{p}=.000\right)$. Results also showed significant mean differencesin the influence of agency culture on commercial crime investigators' effectiveness based on agency type (Custom, EFCC, NDLEA, and Police). Agency culture was found to favour the commercial crime investigators' effectiveness in the Nigeria Police more compared to EFCC, Custom, and NDLEA. Therefore, the hypothesis of no significant mean difference in the influence of agency culture on commercial crime investigators' effectiveness based on agency type cannot be sustained.

The difference observed on the influence of commercial crime investigators' effectiveness based on agency could have been as a result that each agency tends to adopt a relatively uniform perception with common characteristics distinguishing it from the other. Consequently, the employees adopt the common values and norms which control their interaction among themselves and with the outsiders. This is supported by the findings of Baetge, Schewe, Schulz and Solmecke (2007), Nwonyi (2014) and Schein (2010) that agency culture is a link to the performance and success of an organization and embedded in the organization's ability to adapt to its environment. 


\begin{tabular}{|c|c|c|c|c|c|c|c|}
\hline & & & & \multicolumn{4}{|c|}{ Mean Difference } \\
\hline Agencies & $\mathbf{N}$ & Mean & SD & Customs & EFCC & NDLEA & Police \\
\hline Customs & 294 & 52.70 & 19.68 & & & & \\
\hline EFCC & 297 & 77.37 & 13.52 & & -24.67 & & \\
\hline NDLEA & 295 & 78.79 & 14.04 & & & -1.42 & \\
\hline Police & 293 & 56.72 & 17.62 & & & & 22.07 \\
\hline Total & 1179 & & & & & & \\
\hline
\end{tabular}

Table 3: Summary Table of Tukey Posthoc Tests Showing the Mean Differences in Training *The Mean Is Significant at the 0.05 Level

\begin{tabular}{|c|c|c|c|c|c|}
\hline & Sum of Squares & Df & Mean Square & F & Sig. \\
\hline Between Groups & 132.468 & 4 & 33.117 & 8.306 & .007 \\
\hline Within Groups & 4684.725 & 1175 & 3.987 & & \\
\hline Total & 4817.193 & 1179 & & \\
\hline
\end{tabular}

Table 4: Summary Table of One-Way ANOVA Showing Difference in Commercial Crimes Investigation Agencies Effectiveness Based on Agency Training

The mean scores of trainings for Custom, EFCC, NDLEA, and Police are 52.70, 77.37, 78.79, and 56.72 respectively. The result in Table 4 showed a significant influence of training on commercial crime investigators' effectiveness based on agency type $\left(F_{(4,1179)}=8.306, \mathrm{p}=.007\right)$.

Results also showed significant mean differences in the influence of training on commercial crime investigators' effectiveness based on agency type (Custom, EFCC, NDLEA, and Police). Training was found to favour the commercial crime investigators' effectiveness in the NDLEA more compared to EFCC, Custom, and Police. Therefore, the hypothesis of no significant mean difference in the influence of training on commercial crime investigators' effectiveness based on agency type cannot be sustained.

It could then be said from the outcome of this finding that systematic development of knowledge, skills and attitudes required by investigators to perform adequately to meet their organizational needs cannot be over-stressed. This corroborates the report of Olaniyan and Ojo (2008) that training and development are required of employees to enable them work towards taking the organization to its expected destination.

\begin{tabular}{|c|c|c|c|c|c|c|c|}
\hline & & & & \multicolumn{3}{|c|}{ Mean Difference } & Police \\
\hline Agencies & N & Mean & SD & Customs & EFCC & NDLEA & Police \\
\hline Customs & 294 & 77.20 & 19.39 & & & & \\
\hline EFCC & 297 & 83.81 & 17.01 & & -6.61 & & \\
\hline NDLEA & 295 & 89.22 & 11.86 & & & -5.41 & 2.95 \\
\hline Police & 293 & 86.27 & 14.99 & & & & \\
\hline Total & 1179 & & & & & & \\
\hline
\end{tabular}

Table 5: Summary Table of Tukey Posthoc Tests Showing the Mean Differences in Technology Application *The Mean Is Significant at the 0.05 Level

\begin{tabular}{|c|c|c|c|c|c|}
\hline & Sum of Squares & Df & Mean Square & F & Sig. \\
\hline Between Groups & 103.196 & 4 & 25.799 & 5.160 & .000 \\
\hline Within Groups & 5876.175 & 1175 & 5.001 & & \\
\hline Total & 5979.371 & 1179 & \multicolumn{3}{|l}{} \\
\hline
\end{tabular}

Table 6: Summary Table of One-Way ANOVA Showing Difference in Commercial

Crimes Investigation Agencies Effectiveness Based on Technological Application

The commercial crime investigators' mean result on technological application for custom was 77.20, EFCC was 83.81, NDLEA was 89.22 and 86.27 for the Police. The result in Table 6 showed a significant influence of technological application on commercial crime investigators' effectiveness based on agency type $\left(F_{(4,1179)}=5.160, p=.000\right)$. Results also showed significant mean differences in the influence of technological application on commercial crime investigators' effectiveness based on agency type (Custom, EFCC, NDLEA, and Police). Technological application was found to favour the commercial crime investigators' effectiveness in the NDLEA more compared to Police, EFCC, and Custom. Therefore, the hypothesis of no significant mean difference in the influence of technological application on commercial crime investigators' effectiveness based on agency type cannot be sustained.

It could be deduced that since crime is advancing on daily basis, the need to tackle it with more advanced technology is necessary. The result is in line with the previous findings of researchers and scholars like Hindujah, (2007) who found a significant relationship between commercial crimes investigators effectiveness and technological application.

\section{Conclusion}

This study provides the much-needed guide in improving commercial crimes investigators effectiveness. Commercial crimes investigators are in the intelligence sector of law enforcement agencies and their crime fighting, detection and prevention capabilities depend on individual officers' timely access to relevant and accurate information. 
While enforcing the law, they have to decide whether or not a crime has been committed, to investigate the case to gain information and evidence to identify the suspects, to recover the stolen property (e.g., the money), to arrest the suspects, and to bring them to justice by presenting the evidence to the prosecutor. Thus, this finding revealed that agency culture, training and application of technology has substantial impact on law enforcement practices. In addition, any positive relationship that exists between agency culture, training and application of technology by the agency improves the quality of investigation and performance of law enforcement agencies.

Also, the finding of this study is affixed on the importance of understanding the environment and context in which commercial crime investigators must work; the environment of investigating may have substantial effects on the performance of officers' duties. If officers are affected negatively by the environments in which they must live and work, the legitimacy and effectiveness of the agency is threatened. Only through continued research into the area of investigation can this essential institution be significantly improved.

\section{References}

i. Abida, E. \& Irfan, M. (2010). Understanding attitudes towards computer use in the police department of Pakistan. The Electronic Journal on Information Systems in Developing Countries 42(1), 1-26.

ii. Alemika, EEO. (2004). Crime statistics and information management in Nigerian justice and security systems in EEO Alemika and IC Chukwuma (Eds.) Crime and Policing in Nigeria: Challenges and Options, Lagos: Network on Police Reform in Nigeria (NOPRIN)

iii. Alemika, E.O. (2010). History, context and crises of the police in Nigeria. Presentation at the Biennial Retreat of the Police Service Commission on the theme, Repositioning the Nigeria Police to Meet the Challenges of the Policing a Democratic Society in the twenty-First Century and Beyond, held at the Le Meridian Hotel, Uyo, AkwaIbom State, November 1-4, 2010

iv. Baetge, J., Schewe, G., Schulz, R., \&Solmecke, H. (2007). Unternehmenskultur und Unternehmenserfolg: Stand der empirischenForschung und Konsequenzenfür die EntwicklungeinesMesskonzeptes. Journal fürBetriebswirtschaft, 57(3), 183-219

v. Besley, T. F., Persson, T. \& Sturm, D. (2010). Political Competition, Policy and Growth: Theory and Evidence from the United States. Review of Economic Studies, 77, 1329-1352.

vi. Brown, M. F. (2001). Criminal Investigation: Law and Practice. Boston: Butterworth-Heinemann.

vii. Burman, R.; Evans, A.J. (2008). 'Target Zero: A Culture of Safety.'Defence Aviation Safety

viii. Burt, R.S., 1992. Structural Holes: The Social Structure of Competition. Harvard University Press, Cambridge, MA.

ix. Chan, J. (2001). Negotiating the field: New observations on the making of police officers. The Australian and New Zealand Journal of Criminology, 34, 114-133.

x. Chang, M. (2011). Cloud computing technologies and meditation, Merit times A8 Edition, 2011/4/17.

xi. Gbadamosi, L. \&Nwosu, J (2011) Entrepreneurial intention, organizational justice and job satisfaction as determinants of employees' organizational commitment: Evidence from Babcock University Nigeria. Proceedings of informing science \& IT education conference (InSITE), 205-211.

xii. Hee-Jae, C (2000). The Validity and Reliability of the Organizational Culture Questionnaire. Working paper, International Institute for Management Development, 1-16.

xiii. Hinduja, S. (2004). Perceptions of Local and State Law Enforcement Concerning the Role of Computer Crime Investigative Teams. Policing-an International Journal of Police Strategies \& Management, 27(3), 341-357.

xiv. Hinduja, S. (2009). Computer crime investigations in the United States: leveraging knowledge from the past to address the future. International Journal of Cyber Criminology, 1(1), 1-26.

xv. House, R. J., Hanges, P., Javidan, M., Dorfman, P. W., \& Gupta, V. (2004).Culture, leadership and organizations: The GLOBE study of 62 countries. Thousand Oaks, CA: Sage Publications.

xvi. Jones, B.F. and B. A. Olken (2005). Do Leaders Matter? National Leadership and Growth Since World War II.' The Quarterly Journal of Economics 120(3): 835-864.

xvii. Kotter, J. P. \&Heskett, J. L. (1992). Corporate culture and performance. New York: Free Press.

xviii. Kotter, J. (1995). Leading Change: How Transformation Efforts Fail. Harvard Business Review. March-April, 1995; p. 59-67. Retrieved from www.hbr.org

xix. Mullins, L. J. (2008). Essentials of organisational behaviour: Pearson Education.

xx. Nunn, S. \&Quinet, K. (2002). Evaluating the effects of information technology on problem oriented-policing: If it doesn't fit, must we quit? Evaluation Review, 26, 81-108.

xxi. Nwosu, C., Onuoha, L. \&Ayodele, K. O. (2010) Moderator effect of management by objectives on employees' performance in academia. Proceedings of International Conference on Research and Development, 3(41), 57-61.

xxii. Ogunyemi, A. O (2007). Perceived leadership style, motivation and training as predictors of workers' productivity in a manufacturing industry in Lagos State, Nigeria. Ogun Journal of Counselling Studies, (1), 76-83.

xxiii. Ojo, 0 (2009). Impact assessment of corporate culture on employee job performance. Business Intelligence Journal, 2(2), 388-397

xxiv. Olaniyan D.A., \&Ojo, L. (2008). Staff training and development: A vital tool for organisational effectiveness. EuroJournals24(3): 326-331.

xxv. Oledikwa, C. T. \&Nbang, G. G. (2006). Criminal investigators in law enforcement agencies: a new look. Journal of Organization Behaviour, 27(7), 1155-1163 
xxvi. Osterburg, J. \& Ward, R. (2004). Criminal Investigation: A Method for Reconstructing the Past. Cincinnati, OH: Anderson.

xxvii. Osterburg, J. W. (1962). Selection of criminal investigators in law enforcement agencies. Journal of Criminal Law and Criminology, 53(2), 264-268

xxviii. Rojek, J., Kaminski, R.J., Smith, M.R., \&Scheer, C. (2007). South Carolina law enforcement training survey: A national and state analysis. Columbia, SC: University of South Carolina Department of Criminology and Criminal Justice.

xxix. Salami, S.O. (2008). Demographic and psychological predicting organizational commitment among industrial workers. Anthropologist, 10(1), 31-38.

xxx. Schein, E. H. (2010). Organizational culture and leadership (4th ed.). San Francisco, CA: Jossey-Bass.

xxxi. Taylor, S. and Todd, P. (1995) Decomposition and Crossover Effects in the Theory of Planned Behavior: A Study of Consumer Adoption Intentions, International Journal of Research in Marketing, 12, 137-55.

xxxii. Venkatesh, V., \& Davis, F. D. (2000). A theoretical extension of the technology acceptance model: Four longitudinal field studies. Management Science, 46(2), 186-204. 